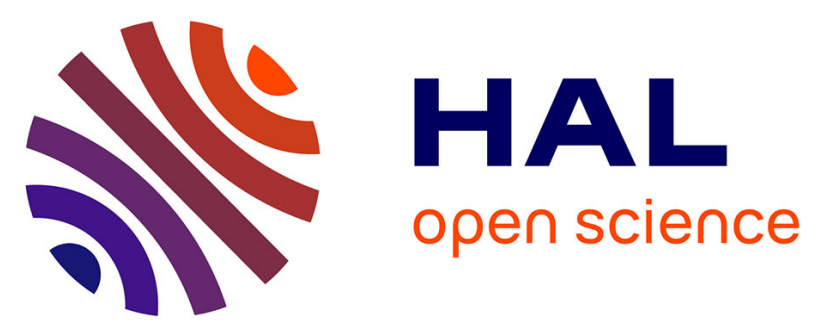

\title{
The use of a ureteral access sheath does not improve stone-free rate after ureteroscopy for upper urinary tract stones.
}

Gaetan Berquet, Paul Prunel, Grégory Verhoest, Romain Mathieu, Karim Bensalah

\section{To cite this version:}

Gaetan Berquet, Paul Prunel, Grégory Verhoest, Romain Mathieu, Karim Bensalah. The use of a ureteral access sheath does not improve stone-free rate after ureteroscopy for upper urinary tract stones.. World Journal of Urology, 2013, 32, pp.229-232. 10.1007/s00345-013-1181-5 . hal-00932522

HAL Id: hal-00932522

https://hal-univ-rennes1.archives-ouvertes.fr/hal-00932522

Submitted on 17 Jan 2014

HAL is a multi-disciplinary open access archive for the deposit and dissemination of scientific research documents, whether they are published or not. The documents may come from teaching and research institutions in France or abroad, or from public or private research centers.
L'archive ouverte pluridisciplinaire HAL, est destinée au dépôt et à la diffusion de documents scientifiques de niveau recherche, publiés ou non, émanant des établissements d'enseignement et de recherche français ou étrangers, des laboratoires publics ou privés. 
The use of a ureteral access sheath does not improve stone free-rate after ureteroscopy for upper urinary tract stones

Gaetan Berquet ${ }^{1}$, Paul Prunel ${ }^{1}$, Grégory Verhoest ${ }^{1}$, Romain Mathieu ${ }^{1}$, Karim Bensalah ${ }^{1}$

${ }^{1}$ Department of Urology, Rennes University Hospital, University of Rennes 1, Rennes, France

Keywords: ureteral access sheath, flexible ureteroscopy, urinary lithiasis, stone-free rate

Abstract : 191 words

Article: 1664 words

Correspondance to:

Gaetan Berquet

Department of Urology

Centre Hospitalier Universitaire Pontchaillou

2 rue Henri Le Guilloux 35000 Rennes, France.

Tel : 0033299283723

Fax : 0033299284113

e-mail: gberquet@hotmail.fr 
Financial disclosures: None declared

Abbreviations:

URS: ureterorenoscopy

UAS: ureteral access sheath

SF: stone free

CT: computerized tomography

KUB: kydney ureters and bladder $\mathrm{x}$-ray 


\section{ABSTRACT}

\section{Purpose}

To evaluate the impact of a ureteral access sheath (UAS) on stone-free (SF) rate after flexible ureteroscopy for upper urinary tract stones.

\section{Materials and methods}

We retrospectively reviewed 280 patients who underwent flexible ureteroscopy (URS) for upper urinary tract stone between 2009 and 2012. Patients were divided into two groups based on whether a UAS was used $(n=157)$ or not $(n=123)$. SF rate was evaluated at one and three months after surgery by abdominal imaging. Quantitative and qualitative variables were compared with Student $t$ test and $\chi 2$ test, respectively. A logistic regression model was used to determine the predictive factors of SF status.

\section{Results}

Stone size was similar in both groups $(15.1 \mathrm{~mm}$ vs. $13.7 \mathrm{~mm}, \mathrm{p}=0.21)$. SF rates at one and three months were comparable in UAS and non UAS groups $(76 \%$ vs. $78 \%$ and $86 \%$ vs. $87 \%, p=0.88$ and 0.89 , respectively). Complication rates were similar in both groups $(12,7 \%$ vs. $12,1 \%, \mathrm{p}=0,78)$. In multivariable analysis, stone size was the only predictive factor of SF rate $(\mathrm{p}=0.016)$.

\section{Conclusion:}

The routine use of a UAS did not improve SF rate in patients undergoing flexible URS for upper urinary tract calculi. 


\section{INTRODUCTION}

Over the last 10 years, flexible ureterorenoscopy (URS) has become an increasingly important option for the treatment of ureteral and kidney stones. Although there is no precise recommendation, concomitant use of a ureteral access sheath (UAS) has been advocated to: 1) facilitate the introduction of the ureteroscope and the extraction of small stone fragments 2) improve per-operative vision and 3) decrease intrarenal pressure ${ }^{1-5}$.

However, the systematic use of a UAS at the time of URS can be questioned. There is little if no evidence of improved operative outcomes after URS with the use of a UAS. Some authors reported an increased stone free (SF) rate ${ }^{6}$ while others did not find any difference whether a UAS was used or not ${ }^{4}$. Moreover, recent studies have shown that UAS could be responsible for ureteral injuries that can occur in up to $50 \%$ of the patients ${ }^{7}$.

In this context, our objective was to evaluate the impact of the use of a UAS on SF rate during flexible URS in patients treated for an upper tract stone.

\section{MATERIELS AND METHODS}

We retrospectively collected the data of patients who underwent flexible URS at our institution between May 2009 and January 2012. We had a total of 359 cases. We excluded URS performed in children (eight cases), URS made for the diagnosis and treatment of upper urinary tract urothelial tumours (10 cases), and patients who had several procedures for the same calculus (61 cases). This yielded a total of 280 flexible URS performed to treat a kidney or ureteral stone in one procedure.

The following parameters were collected: age, sex, BMI, ASA score, stone size (larger diameter calculated on CT scan), number of stones, stone location (coded as ureter, pelvis, inferior calyx, medium calyx and upper calyx), operative time, fluoroscopy time, use of a 
UAS, pre and post-operative stenting, occurrence of post operative complications (graded according to the Clavien system), and length of hospital stay.

SF status was evaluated at one month and three months using abdominal ultrasound or CT scan. Based on most publications, we considered that the patient was SF if there was less than one residual fragment with a diameter $<3 \mathrm{~mm}$.

Surgical technique. Our standard technique begins with rigid cystoscopy and placement of a 0.035 inch PTFE hydrophilic guide wire up to the kidney under fluoroscopic guidance. The use of a UAS is left at the surgeon discretion. We don't routinely use a UAS unless we want to remove as many fragments as possible (such as in the case of infectious or cystine stone) or if the endoscope cannot pass the ureteral orifice. If needed, we use a 12-14 Fr hydrophilic UAS (Flexor ${ }^{\circledR}$, Cook medical, Limerick, Ireland). If we don’t use any UAS, the flexible ureteroscope is passed up to the kidney over the working guide wire under fluoroscopic guidance. Stones are fragmented with a $273 \mu \mathrm{m}$ holmium laser fibre into dust. We usually remove two fragments for stone analysis. At the end of the procedure, a double $\mathbf{J}$ stent can be placed according to surgeon's impression. It is removed one week later in the absence of residual fragment.

Statistical analysis. We compared the two groups (with or without UAS) using Student $\mathrm{t}$ and $\chi^{2}$ test for quantitative and categorical variables, respectively. A logistic regression model was used to identify predictive factors of SF rate. Statistical analysis was performed with SPSS 17.0 software. A p value $<0.05$ was considered to be significant.

\section{RESULTS}

There were 280 flexible URS in 280 patients including 123 without UAS and 157 with UAS. Patients' and stones' characteristics are listed in table 1. There was a larger proportion 
of men in the UAS group (sex ratio 1.7 vs. $1, \mathrm{p}=0.03$ ). Stone sizes were similar in both groups but there was a tendency for an increased number of stones in the UAS group, although not significant ( 1.9 vs. $1.6, \mathrm{p}=0.07)$. There were more ureteral stones in the non UAS group (30\% vs. $9 \%, p<0.001)$ but there were no differences in the repartition of kidney stones particularly for lower pole stones. Operative and post-operative characteristics for both groups are described in table 2. Operative time was 10 minutes shorter in the non UAS group (76 min vs. $86 \mathrm{~min}, \mathrm{p}=0.06$ ). $36 \%$ of the patients had a ureteral stent before flexible URS, $50 \%$ in the non UAS group vs. $24 \%$ in the UAS group ( $<<0.001)$. The severity of postoperative complications was assessed according to the Clavien classification ${ }^{8}$. Complications were mostly minor and there were no differences between UAS and non UAS groups $(12.7 \%$ vs. $12.1 \%, \mathrm{p}=0.78)$.

SF rates are described in table 3. Overall SF rates at one and three months were comparable with or without UAS (76\% vs. $78 \%$ and $86 \%$ vs. $87 \%, \mathrm{p}=0.88$ and 0.89 , respectively). Best results were obtained for ureteral and upper kidney stones and there were no differences according to stone location. When considering the SF rate at three months, stone size was the only independent predictive factor in multivariable analysis $(\mathrm{p}=0.016)$. Age $(\mathrm{p}=0,76)$, BMI $(\mathrm{p}=0,23)$, stone location, number of stones $(0.7)$, use of a UAS $(\mathrm{p}=0,21)$, preoperative stenting $(\mathrm{p}=0.15)$ and postoperative stenting $(\mathrm{p}=0,26)$ had no impact on stone free rate (table 4).

\section{DISCUSSION}

Recent advances in URS have transformed the management of urolithiasis ${ }^{9}$. Smaller and more durable flexible endoscopes and new laser technology enable full access to the collecting system and vaporisation of any kind of stone ${ }^{10,11}$. Flexible URS is performed at 
many institutions worldwide and recommended as one of the treatments of choice for ureteral and kidney stones ${ }^{12}$. According to European Association of Urology guidelines, flexible URS is recommended as first line treatment for kidney stones $<2 \mathrm{~cm}$ and as second line treatment in kidney stones $>2 \mathrm{~cm}$ in case of failure of percutaneous nephrolithotomy ${ }^{13,14}$

The use of a UAS has traditionally been advocated for flexible URS ${ }^{15}$. UAS supposedly have some advantages: 1) they allow easy multiple access to the upper urinary tract and therefore significantly facilitate flexible URS 2) they are supposed to improve vision by optimizing irrigation flow and 3) they decrease intra renal pressure which could potentially diminish kidney injury ${ }^{1-5}$. However, there is currently no official recommendation as to the use of a UAS during flexible URS. Furthermore, evidence on the impact of UAS on perioperative outcomes as well as SF rates is very limited ${ }^{4,6}$.

We did not find any difference in terms of SF rate between patients who had been treated with or without a UAS. In multivariable analysis, stone size was the only predictive factor of SF rate $(\mathrm{p}=0.016)$. The use of a UAS, stone location and/or the number of stones had no impact on SF rate. Few studies have previously addressed this issue. Kourambas and al found no difference in SF rates according to the use of a UAS (78\% in the UAS group versus $85 \%$ in the non UAS group) ${ }^{4}$. On the contrary, others reported an improved SF rate when URS was performed with a UAS ${ }^{6}$. However, this difference disappeared when groups were stratified by stone location, which was not the case in our study where we did not observe any difference in SF rate whatever the stone location.

Proponents of UAS state that they can increase the irrigation flow thereby flushing stone fragments out ${ }^{1}$. Our results do not support this hypothesis. In our practice, we fragment all stone burden in very small particles and do not try to remove every single stone fragment.

Overall, our SF rates are similar to those recently published ${ }^{6,12,16-18}$. Most of the studies published over the last 10 years report SF rates ranging from $79 \%$ to $100 \%{ }^{6,12,18}$. In a 
recent review of the literature, Aboumarzouk reports a mean SF rate of $87.5 \%{ }^{16,17}$. These numbers must be analyzed with caution because there is no consensus on the precise definition of a residual fragment as well as a wide variability in imaging modalities used to evaluate stone clearance ${ }^{19}$. We routinely evaluate stone clearance with a KUB and an abdominal ultrasound to avoid the unnecessary radiation of the CT scan. We arbitrarily chose a cut-off of $3 \mathrm{~mm}$ to define a residual stone fragment since those small stones are unlikely to become symptomatic ${ }^{20-22}$ and we rather advise active metabolic evaluation and medical treatment to avoid recurrence ${ }^{23}$.

We did not observe any difference in terms of complications between UAS and non UAS patients. However, UAS can be responsible for per and postoperative complications such as ureteral perforation, mucosal injury, urinary extravasation, ureteral avulsion and ureteral stricture ${ }^{2,24,25}$. According to a recent study in which the authors carefully examined ureteral integrity after the use of a UAS, there was an incidence of $50 \%$ of iatrogenic ureteral lesions ${ }^{7}$.

Two studies demonstrated that a UAS can reduce intrarenal pressure ${ }^{3,5}$. Nevertheless, no impact on renal function preservation has been proven ${ }^{3,5}$. On the contrary, Lallas and al demonstrated that UAS was associated with a transient decrease of ureteral blood flow ${ }^{25}$, which could potentially lead to further ureteral stricture ${ }^{26}$.

There are some limitations to our study. This is a retrospective review from a single institution with a relatively small population. The choice of using a UAS is left at the surgeon's discretion so there might be some selection biases even if we did not find any difference in terms of stone characteristics. The frequency of ureteral stones was more important in the non UAS group (30\% vs. 9\%), which might have indirectly improved the results of non-UAS patients. However, when comparing the sub-groups of patients with 
stones only located in the kidney, we did not find any difference in terms of stone free rate $(85 \%$ vs. $81 \%, \mathrm{p}=0.7)$.

\section{CONCLUSION}

In our experience the use of a UAS did not improve SF rate in patients undergoing flexible URS for upper urinary tract stone. The only predictive factor of SF status was stone size. These results must be confirmed by prospective randomized trials. 


\section{REFERENCES}

1. Stern JM, Yiee J and Park S: Safety and efficacy of ureteral access sheaths. J Endourol. 21: 119-23, 2007.

2. Vanlangendonck $\mathrm{R}$ and Landman $\mathrm{J}$ : Ureteral access strategies: pro-access sheath. Urol Clin North Am. 31: 71-81, 2004.

3. Rehman J, Monga M, Landman J, et al: Characterization of intrapelvic pressure during ureteropyeloscopy with ureteral access sheaths. Urology. 61: 713-8, 2003.

4. Kourambas J, Byrne RR and Preminger GM: Does a ureteral access sheath facilitate ureteroscopy? J Urol. 165: 789-93, 2001.

5. Auge BK, Pietrow PK, Lallas CD, et al: Ureteral access sheath provides protection against elevated renal pressures during routine flexible ureteroscopic stone manipulation. J Endourol. 18: 33-6, 2004.

6. L'Esperance J O, Ekeruo WO, Scales CD, Jr., et al: Effect of ureteral access sheath on stone-free rates in patients undergoing ureteroscopic management of renal calculi. Urology. 66: 252-5, 2005.

7. Traxer $O$ and Thomas A: Prospective evaluation and classification of ureteral wall injuries resulting from insertion of a ureteral access sheath during retrograde intrarenal surgery. J Urol. 189: 580-4, 2013.

8. Dindo D, Demartines $\mathrm{N}$ and Clavien PA: Classification of surgical complications: a new proposal with evaluation in a cohort of 6336 patients and results of a survey. Ann Surg. 240: 205-13, 2004.

9. Wignall GR, Canales BK, Denstedt JD, et al: Minimally invasive approaches to upper urinary tract urolithiasis. Urol Clin North Am. 35: 441-54, viii, 2008.

10. Chow GK, Patterson DE, Blute ML, et al JW: Ureteroscopy: effect of technology and technique on clinical practice. J Urol. 170: 99-102, 2003.

11. Wendt-Nordahl G, Mut T, Krombach $\mathrm{P}$, et al: Do new generation flexible ureterorenoscopes offer a higher treatment success than their predecessors? Urol Res. 39: 185-8, 2011.

12. Breda A, Ogunyemi O, Leppert JT, et al: Flexible ureteroscopy and laser lithotripsy for multiple unilateral intrarenal stones. Eur Urol. 55: 1190-6, 2009.

13. Preminger GM: Management of lower pole renal calculi: shock wave lithotripsy versus percutaneous nephrolithotomy versus flexible ureteroscopy. Urol Res. 34: 108-11, 2006.

14. Srisubat A, Potisat S, Lojanapiwat B, et al: Extracorporeal shock wave lithotripsy (ESWL) versus percutaneous nephrolithotomy (PCNL) or retrograde intrarenal surgery (RIRS) for kidney stones. Cochrane Database Syst Rev: CD007044, 2009.

15. Takayasu $\mathrm{H}$ and Aso $\mathrm{Y}$ : Recent development for pyeloureteroscopy: guide tube method for its introduction into the ureter. J Urol. 112: 176-8, 1974.

16. Aboumarzouk OM, Monga M, Kata SG, et al: Flexible Ureteroscopy and Laser Lithotripsy for Stones $>2 \mathrm{~cm}$ : A Systematic Review and Meta-Analysis. J Endourol, 2012.

17. Aboumarzouk OM, Somani B and Monga $M$ : Safety and efficacy of ureteroscopic lithotripsy for stone disease in obese patients: a systematic review of the literature. BJU Int, 2012. 
18. Sofer M, Watterson JD, Wollin TA, et al: Holmium:YAG laser lithotripsy for upper urinary tract calculi in 598 patients. J Urol. 167: 31-4, 2002.

19. Hyams ES, Bruhn A, Lipkin M, et al: Heterogeneity in the reporting of disease characteristics and treatment outcomes in studies evaluating treatments for nephrolithiasis. J Endourol. 24: 1411-4, 2010.

20. Rebuck DA, Macejko A, Bhalani $V$, et al: The natural history of renal stone fragments following ureteroscopy. Urology. 77: 564-8, 2011.

21. El-Nahas AR, El-Assmy AM, Madbouly $\mathrm{K}$, et al: Predictors of clinical significance of residual fragments after extracorporeal shockwave lithotripsy for renal stones. J Endourol. 20: 870-4, 2006.

22. Buchholz NP, Meier-Padel $S$ and Rutishauser G: Minor residual fragments after extracorporeal shockwave lithotripsy: spontaneous clearance or risk factor for recurrent stone formation? J Endourol. 11: 227-32, 1997.

23. Kang DE, Maloney MM, Haleblian GE, et al: Effect of medical management on recurrent stone formation following percutaneous nephrolithotomy. J Urol. 177: 1785-8; discussion 1788-9, 2007.

24. Abrahams HM and Stoller ML: The argument against the routine use of ureteral access sheaths. Urol Clin North Am. 31: 83-7, 2004.

25. Lallas CD, Auge BK, Raj GV, et al: Laser Doppler flowmetric determination of ureteral blood flow after ureteral access sheath placement. J Endourol. 16: 583-90, 2002.

26. Delvecchio FC, Auge BK, Brizuela RM, et al: Assessment of stricture formation with the ureteral access sheath. Urology. 61: 518-22; discussion 522, 2003. 
Table 1: Patients and stones' characteristics

\begin{tabular}{|c|c|c|c|}
\hline & UAS group & Non UAS group & $P$ value \\
\hline $\mathrm{N}$ & 157 & 123 & \\
\hline Mean Age $( \pm S D)$ & $50( \pm 15.2)$ & $52( \pm 17.3)$ & 0.34 \\
\hline Sex ratio $(M / F)$ & 1.7 & 1 & 0.034 \\
\hline BMI $\left(\mathrm{kg} / \mathrm{m}^{2}\right)( \pm \mathrm{SD})$ & $24.9( \pm 3.9)$ & $26.5( \pm 6.2)$ & 0.026 \\
\hline $\begin{array}{c}\text { Mean number of } \\
\text { stones }( \pm S D)\end{array}$ & $1.92( \pm 1.5)$ & $1.61( \pm 1.1)$ & 0.07 \\
\hline $\begin{array}{l}\text { Mean stone size } \\
\quad(\mathrm{cm} \pm \mathrm{SD})\end{array}$ & $15.15( \pm 9.8)$ & $13.75( \pm 8.0)$ & 0.21 \\
\hline \multicolumn{4}{|l|}{ Stone location } \\
\hline Ureter & $10(9 \%)$ & $27(30 \%)$ & $<0.001$ \\
\hline Upper-pole & $8(7 \%)$ & $7(8 \%)$ & 0.91 \\
\hline Mid-pole & $17(15 \%)$ & $11(12 \%)$ & 0.48 \\
\hline Lower-pole & $48(44 \%)$ & $30(33 \%)$ & 0.11 \\
\hline Renal pelvis & $25(23 \%)$ & $14(15 \%)$ & 0.18 \\
\hline
\end{tabular}


Table 2: Operative and post-operative outcomes

\begin{tabular}{cccc}
\hline & UAS group & Non UAS group & P value \\
\hline $\mathrm{N}$ & 157 & 123 & \\
$\begin{array}{c}\text { Fluoroscopy time }(\mathrm{sec}) \\
( \pm \text { SD })\end{array}$ & $117( \pm 119)$ & $92( \pm 88)$ & 0.1 \\
$\begin{array}{c}\text { Lenght of stay (days) }( \pm \\
\text { SD) }\end{array}$ & $2.04( \pm 1.2)$ & $2.01( \pm 1.5)$ & 0.86 \\
$\begin{array}{c}\text { Mean operative time } \\
\text { (min) }( \pm \text { SD) }\end{array}$ & $86( \pm 37)$ & $76( \pm 36)$ & 0.06 \\
$\begin{array}{c}\text { Pre-operative urétéral } \\
\text { stent }\end{array}$ & $39(24 \%)$ & $62(50 \%)$ & 0.001 \\
Post-operative ureteral \\
stent
\end{tabular}


Table 3: SF rates at three months according to stone location.

\begin{tabular}{cccc}
\hline & UAS group & Non UAS group & P value \\
\hline Overall & 86 & 87 & 0.89 \\
Ureter & 100 & 96 & 0.53 \\
Overall kidney & 85 & 81 & 0.67 \\
Renal pelvis & 96 & 92 & 0.66 \\
Lower pole & 79 & 80 & 0.92 \\
Mid pole & 88 & 81 & 0.63 \\
Upper pole & 100 & 85 & 0.26 \\
\hline
\end{tabular}


Table 4: Multivariable analysis: predictive factors of SF rate at three months

\begin{tabular}{lc}
\hline Variables & $\mathrm{p}$ \\
\hline Age & 0.76 \\
BMI & 0.23 \\
Stone size & 0.016 \\
Number of stones & 0.7 \\
UAS (yes/no) & 0.21 \\
Pre operative stent & 0.15 \\
Post operative stent & 0.26 \\
Stone location & 0.21 \\
\end{tabular}

